\title{
Failure of compression molded all-polyolefin composites studied by acoustic emission
}

\author{
I. Z. Halász ${ }^{1}$, G. Romhány ${ }^{1}$, Á. Kmetty ${ }^{1,2}$, T. Bárány ${ }^{1 *}$, T. Czigány $y^{1,2}$ \\ ${ }^{1}$ Department of Polymer Engineering, Faculty of Mechanical Engineering, Budapest University of Technology and \\ Economics, Múegyetem rkp. 3., H-1111 Budapest, Hungary \\ ${ }^{2}$ MTA-BME Research Group for Composite Science and Technology, Műegyetem rkp. 3., H-1111 Budapest, Hungary
}

Received 12 October 2014; accepted in revised form 24 December 2014

\begin{abstract}
This paper is aimed at studying the failure behavior of polyolefin-based self-reinforced polymer composites (SRPCs) via acoustic emission (AE). Three matrix materials (ethylene octene copolymer (EOC), polypropylene-based thermoplastic elastomer (ePP), random polypropylene copolymer (rPP), and three kinds of reinforcing structures of PP homopolymer (unidirectional (UD), cross-ply (CP) and woven fabric (WF)) were used. SRPCs were produced by compression molding using the film-stacking method. The composites were characterized by mechanical tests combined with in situ assessment of the burst-type AE events. The results showed that rPP matrix and UD reinforcement produced the greatest reinforcement, with a tensile strength more than six times as high as that of the matrix and a Young's modulus nearly doubled compared to the neat matrix. The number of the detected AE events increased with increasing Young's modulus of the applied matrices being associated with reduced sound damping. The AE amplitude distributions shows that failure of the SRPC structure produces AE signals in a broad amplitude range, but the highest detected amplitude range can be clearly linked to fiber fractures.
\end{abstract}

Keywords: polymer composites, all-polymer composite, compression molding, film-stacking method, acoustic emission

\section{Introduction}

Nowadays self-reinforced polymer composites (SRPCs) [1] are being developed dynamically. SRPCs can be produced by compaction [2], coextrusion [3], film-stacking [4, 5] or a combination of these methods [6]. The goal in each case is the production of a thermoplastic polymer composite that has excellent mechanical properties and can be recycled easily and cost effectively. In order to widely use these composites, however, it is necessary to investigate them with special regard of failure. An excellent method to characterize the failure is a tensile test combined with an acoustic emission (AE) test. When a material undergoes irreversible changes, for example crack formation, fracture of the matrix, delamination, or fiber fracture, then the release of the stored energy produces a transient elastic wave on the surface which can be recorded an analyzed by AE. Considering some characteristics (amplitude, number) of these burst-type AE events and observing simultaneously the actual failure by suitable visual techniques the failure mechanisms and sequences in the composite can be identified.

Many researchers already used the AE to examine the failure of SRPCs. Zhuang and Yan [7] verified the viability of this method for an ultra-high molecular weight polyethylene (UHMWPE)/high density polyethylene (HDPE) based self-reinforced composite. They produced self-reinforced composites with 50\% nominal UHMWPE fiber content and with different fiber alignments. According to their $\mathrm{AE}$ results fiber-matrix debonding caused AE sig-

\footnotetext{
${ }^{\text {*Corresponding author, e-mail: barany@eik.bme.hu }}$

(C) BME-PT
} 
nals with amplitudes in the range of $30-45 \mathrm{~dB}$. For matrix deformation and fracture an $\mathrm{AE}$ amplitude range of 30-60 dB, for fiber pullout $60-80 \mathrm{~dB}$, while for fiber fracture and delaminations $60-85 \mathrm{~dB}$ were given. Scanning electron microscopic (SEM) images were used to corroborate the results. Cabrera et al. [8] successfully used AE method to record damage initiation events under static tensile measurements of coextruded self-reinforced PP composites. Romhány et al. [9] investigated the fracture toughness and compaction quality of PP-based self-reinforced composites $\left(\mathrm{Curv}^{\circledR}\right)$ with $\mathrm{AE}$. In their tests single edge notched tensile loaded (SEN-T type) specimens were used. AE signals were collected with one and four microphones. It was shown that the damage development can well be assessed based on the localized $\mathrm{AE}$ events. The course of the AE hits as a function of loading of the specimens indicated well the consolidation quality. The relationship between consolidation quality and course of the $\mathrm{AE}$ events during loading was verified by Izer et al. [10]. In their tests $50 \mathrm{wt} \% \alpha$-PP fabric was used as reinforcement and self-reinforced composite specimens were manufactured from three ( $\beta$-PP, random PP, and $\beta$-phase random $\mathrm{PP}$ ) matrices by film-stacking at various pressing temperatures. The failure of each specimen was investigated in tensile test combined with $\mathrm{AE}$ recording. It was found that the number of $\mathrm{AE}$ events depends on the interfacial adhesion between reinforcement and matrix in the composite. With improving consolidation the number of AE events decreased markedly. In poorly consolidated composites the number of $\mathrm{AE}$ events reached several thousands by contrast to a well consolidated one with several tens. Low amplitude (40-50 dB) AE signals were assigned to sliding of tapes within the corresponding fabric or to delaminations, while signals' amplitudes above $65 \mathrm{~dB}$ were traced to fiber/tape fracture.

The goal of this study was to characterize the fracture behavior of polyolefin-based self-reinforced composites by acoustic emission. The SRPCs are made by compression molding from different matrices with different Young's moduli, reinforced with various reinforcing structures composed of PP homopolymer (hPP). It was expected that the matrix characteristics, changing from 'soft' rubber to 'hard' thermoplastic, affect the AE characteristics.

\section{Materials and processing}

As matrix material three kinds of materials were used, which are listed in Table 1.

The basic composition of the ePP was the same as that of rPP according to Fourier-transform infrared (FTIR) analysis. Accordingly, rPP and ePP matrix materials belong to the same polymer family. From the matrix granulates a $50 \mu \mathrm{m}$ thick film was prepared by cast film extrusion.

As reinforcement woven polypropylene fabric from highly oriented split polypropylene homopolymer tapes $\left(180 \mathrm{~g} / \mathrm{m}^{2}, T_{\mathrm{m}}=172.4^{\circ} \mathrm{C}\right.$ (determined by differential scanning calorimetry (DSC)), tensile strength $465 \pm 32 \mathrm{MPa}$ (measured on a single tape)) Zwick Z050 tensile machine)) and a highly oriented polypropylene homopolymer (hPP) multifilament (linear density: $3300 \mathrm{dtex}, T_{\mathrm{m}}=172.1^{\circ} \mathrm{C}$ (determined by DSC), number of single fibers: 400 , tensile strength $581 \pm 30 \mathrm{MPa}$, (Stradom S.A., Czestochowa, Poland)) were applied. Three kinds of reinforcement structures were used: unidirectional reinforcement (UD), the cross-ply (CP) $\left(0-90^{\circ}\right)$ arrangement and the woven fabric (WF). The reinforcing hPP multifilaments were filament wound onto an aluminum core and matrix films were inserted in between the wound layers, as already published in the literature [6]. The woven fabric layers were inserted between the matrix films. The related 'package' was consolidated by compression molding (Schwabentan Polystat $300 \mathrm{~S})$. The production parameters are listed in Table 2. During preheating the 'package' to be consolidated was in the press without pressure.

Table 1. Matrix materials and their abbreviations

\begin{tabular}{|l|l|c|c|l|l|}
\hline \multicolumn{1}{|c|}{ Matrix material } & Abbreviation & $\begin{array}{c}\mathbf{T}_{\mathbf{m}}{ }^{*} \\
{\left[{ }^{\circ} \mathbf{C}\right]}\end{array}$ & $\begin{array}{c}\text { MFI } \\
{[\mathbf{g} / \mathbf{1 0} \mathbf{~ m i n}]}\end{array}$ & \multicolumn{1}{|c|}{ Brand name } & \multicolumn{1}{|c|}{ Producer } \\
\hline Ethylene-octene copolymer & EOC & 100.3 & $30^{* *}$ & Engage 8402 & Dow Chemical Company \\
\hline Polypropylene based thermoplastic elastomer & ePP & 84.2 & $25^{* * *}$ & Versify 4200 & Dow Chemical Company \\
\hline Random PP copolymer & rPP & 148.4 & $45^{* * *}$ & Tipplen R959A & TVK Tiszaújváros, Hungary \\
\hline
\end{tabular}

*determined by DSC from the first melting curve, $10^{\circ} \mathrm{C} / \mathrm{min}$

${ }^{* *} 190^{\circ} \mathrm{C}$ with $2.16 \mathrm{~kg}$

${ }^{* * *} 230^{\circ} \mathrm{C}$ with $2.16 \mathrm{~kg}$ 
Table 2. Production parameters of SRPCs

\begin{tabular}{|c|c|c|c|c|c|}
\hline Matrix & $\begin{array}{c}\text { Reinforcing } \\
\text { structure }\end{array}$ & $\begin{array}{c}\text { Pressing temperature } \\
{\left[{ }^{\circ} \mathrm{C}\right]}\end{array}$ & $\begin{array}{c}\text { Preheat time } \\
\text { [min] }\end{array}$ & $\begin{array}{l}\text { Pressing time } \\
\text { [min] }\end{array}$ & $\begin{array}{c}\text { Compression pressure } \\
{[\mathrm{MPa}]}\end{array}$ \\
\hline \multirow{3}{*}{ EOC } & UD & \multirow{6}{*}{140} & 4 & 6 & \multirow{9}{*}{5.3} \\
\hline & $\mathrm{CP}$ & & 4 & 6 & \\
\hline & WF & & 1.5 & 4 & \\
\hline \multirow{3}{*}{ ePP } & UD & & 4 & 8 & \\
\hline & $\mathrm{CP}$ & & 4 & 8 & \\
\hline & WF & & 1.5 & 4 & \\
\hline \multirow{3}{*}{$\mathrm{rPP}$} & UD & \multirow{3}{*}{180} & 4 & 4 & \\
\hline & $\mathrm{CP}$ & & 4 & 4 & \\
\hline & WF & & 1.5 & 4 & \\
\hline
\end{tabular}

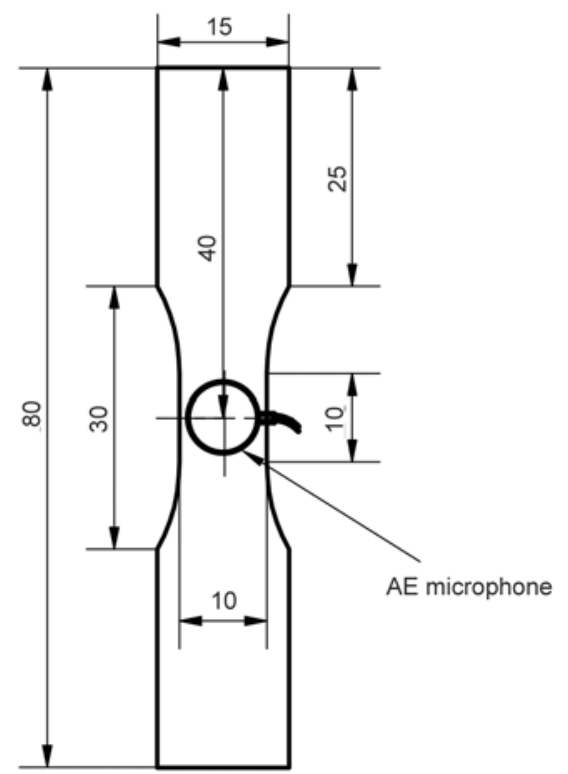

Figure 1. Measurement layout and the main dimensions of the specimen (dimensions in $\mathrm{mm}$ )

The thickness of the resulting composite plates was between $0.9 \ldots 2.6 \mathrm{~mm}$. Nominal fiber content was set to $75 \mathrm{wt} \%$. From the composite plates the specimens (as shown in Figure 1) were cut with the help of a water-jet cutter.

\section{Testing methods}

The tensile tests were carried out on a Zwick Z020 (Zwick GmbH, Ulm, Germany) universal testing machine at a testing speed of $5 \mathrm{~mm} / \mathrm{min}$ and a clamping length of $30 \mathrm{~mm}$. Five parallel tests were run on each SRPC and the tensile strength (determined at maximal force), tensile modulus and strain at break were determined. AE measurements were carried out with a Sensophone AED-40 (Sensophone Kft, Hungary) apparatus and wideband $(100-600 \mathrm{kHz})$ Micro30D (Physical Acoustics Corporation, USA) microphone and a logarithmic amplifier. The reference level for the amplitude of the signals was $1 \mu \mathrm{V}$. The cumulated number of events and the amplitude distribution of the measured values were evaluated to map the relationship between the failure of the materials and the emitted acoustic signals.

\section{Results and discussion}

Table 3 contains the results of the tensile tests. As expected, a considerable increase was observed in the Young's modulus and tensile strength due to the reinforcements. This strengthening effect was most pronounced for the UD reinforcing structure. The tensile strength and Young's modulus of the SRPCs reinforced with woven fabric and CP structure did not differ significantly as a function of the testing direction (i.e. warp, weft). There was, however, a large difference between the Young's moduli and tensile strength values of the composites with identical reinforcement structure: these values increased with increasing Young's moduli of the matrix materials. For all matrices the strain at break was the highest for the fabric (WF) reinforced composites. This was expected considering the fact that in the UD and CP structuring the fibers are straight, while they are wavy in the fabric and straighten in some extent only during loading.

When the polished cross sections of the composites are examined (Figure 2), it can be seen that the distribution of the reinforcement fibers was better in the case of the EOC matrix (note that EOC had better flowability) than in the case of the ePP matrix. With CP reinforcement the original fiber directions became less distorted, while with UD it can also be seen that the fibers are more evenly distributed along the cross-section. Pressing at higher temperatures also led to a decrease in the thickness of the manufactured plates for the rPP matrix compared to the other two matrices (EOC: $2.0-2.5 \mathrm{~mm}$, ePP: 2.1-2.6 mm rPP: 0.9- $1.7 \mathrm{~mm}$ ).

When evaluating the AE test results, first the amplitude distribution of the events was analyzed to find 
Table 3. Mechanical properties of the composites

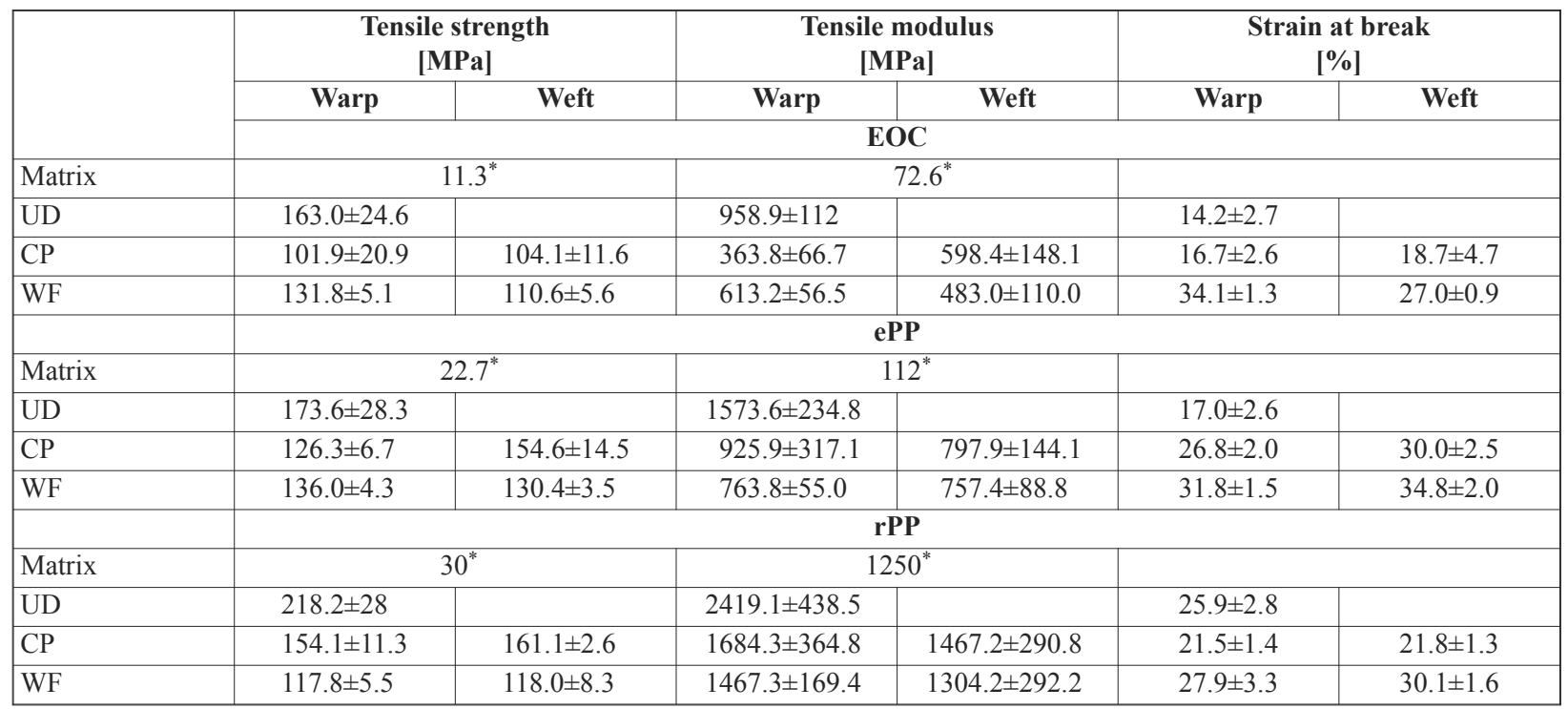

${ }^{*}$ The values for the matrix are values provided by the manufacturer
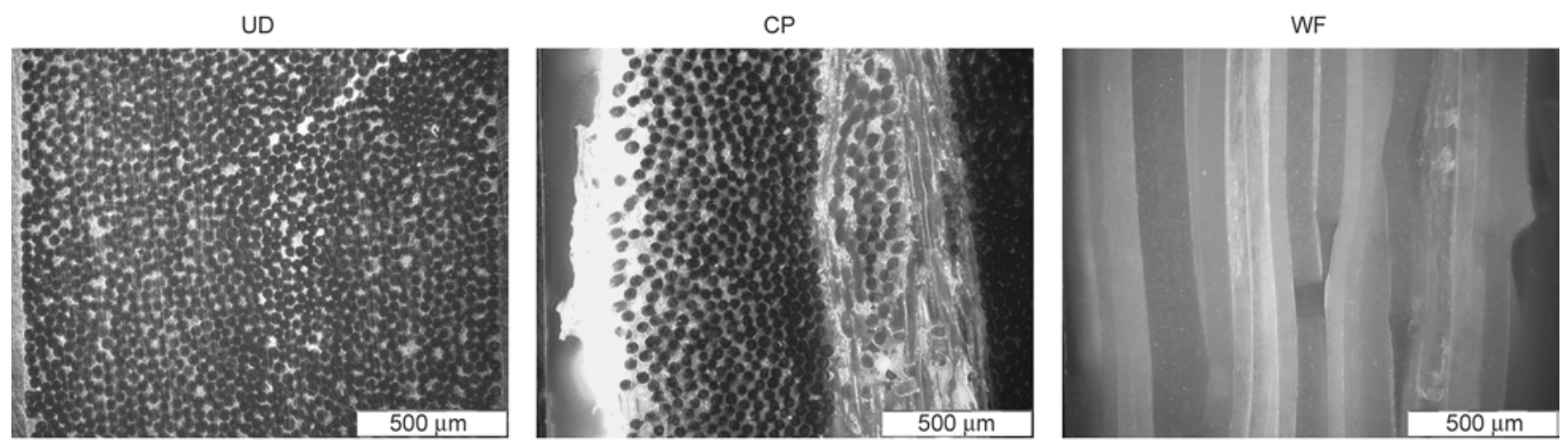

EOC
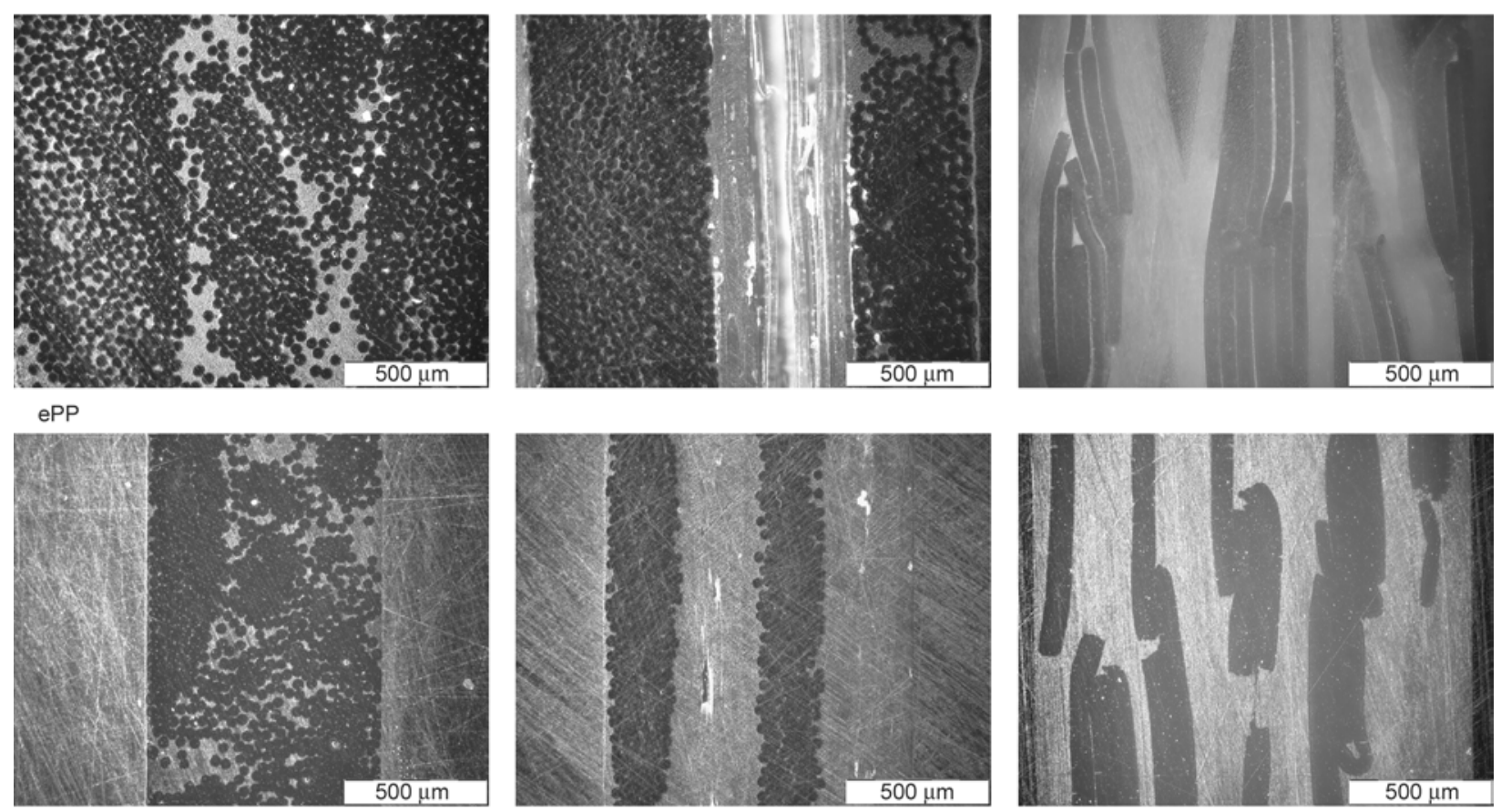

rPP

Figure 2. Polished cross-section images of the composites 


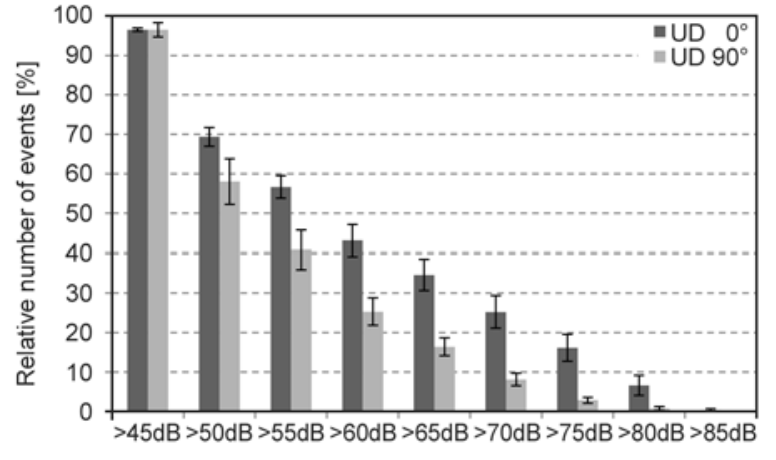

a)

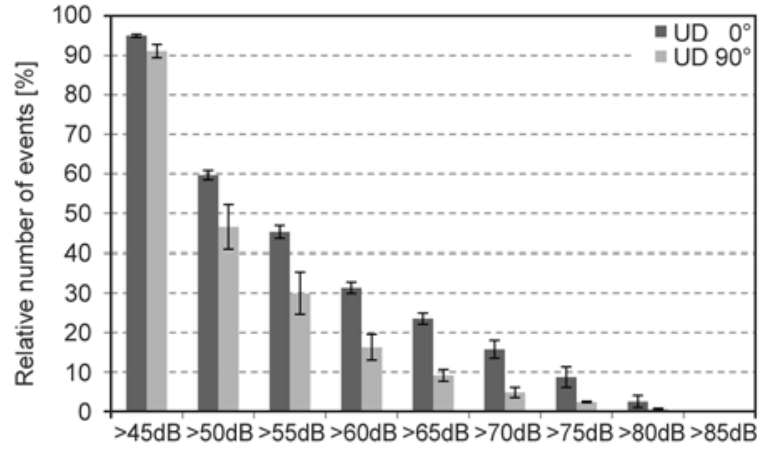

b)

Figure 3. Relative number of events in the case of rPP (a) and ePP (b) matrix composites

a relationship between the amplitudes of the detected signals and the events of the various failures generating these signals. To assign AE signals specifically associated with fiber fracture, tests were run on UD reinforced SRPCs in both parallel and perpendicular directions to the loading and the collected AE signals were compared. Since fiber fracture does not occur when fibers are exposed to perpendicular load, a comparison of the amplitude distributions of the AE signals in these two directions provides information for fiber fracture. In the case of loading perpendicular to the reinforcing fibers no signals were detected until the maximal force was reached.

Figure 3 shows the relative number of AE events in the tensile tests of rPP and ePP matrix-based UD composites, representing the percentage of the events with higher amplitude than a given amplitude threshold. It can be seen that as amplitude increases, the difference between the two directions becomes larger. This points to the fact that signals associated with fiber fracture are detectable at higher intensity than signals associated with other failure modes (namely debonding). This is only true for AE events occurring in the immediate vicinity of the microphone because the amplitude values of long-range fiber fractures get lower due to the dampening effect of the material. Figure 3 shows that signals above $75 \mathrm{~dB}$ amplitude almost exclusively appear when the reinforcing hPP fibers are parallel to the loading direction. Therefore, if such signals are detected during AE test in an SRPC of unknown structure, one can surmise that the alignment of the reinforcing phase is parallel to the loading. The same tendency was observed in the case of SRPCs with EOC matrix. In this SRPC the detected signals were shifted to lower amplitudes due to the more effective dampening of this 'rubbery' EOC matrix.
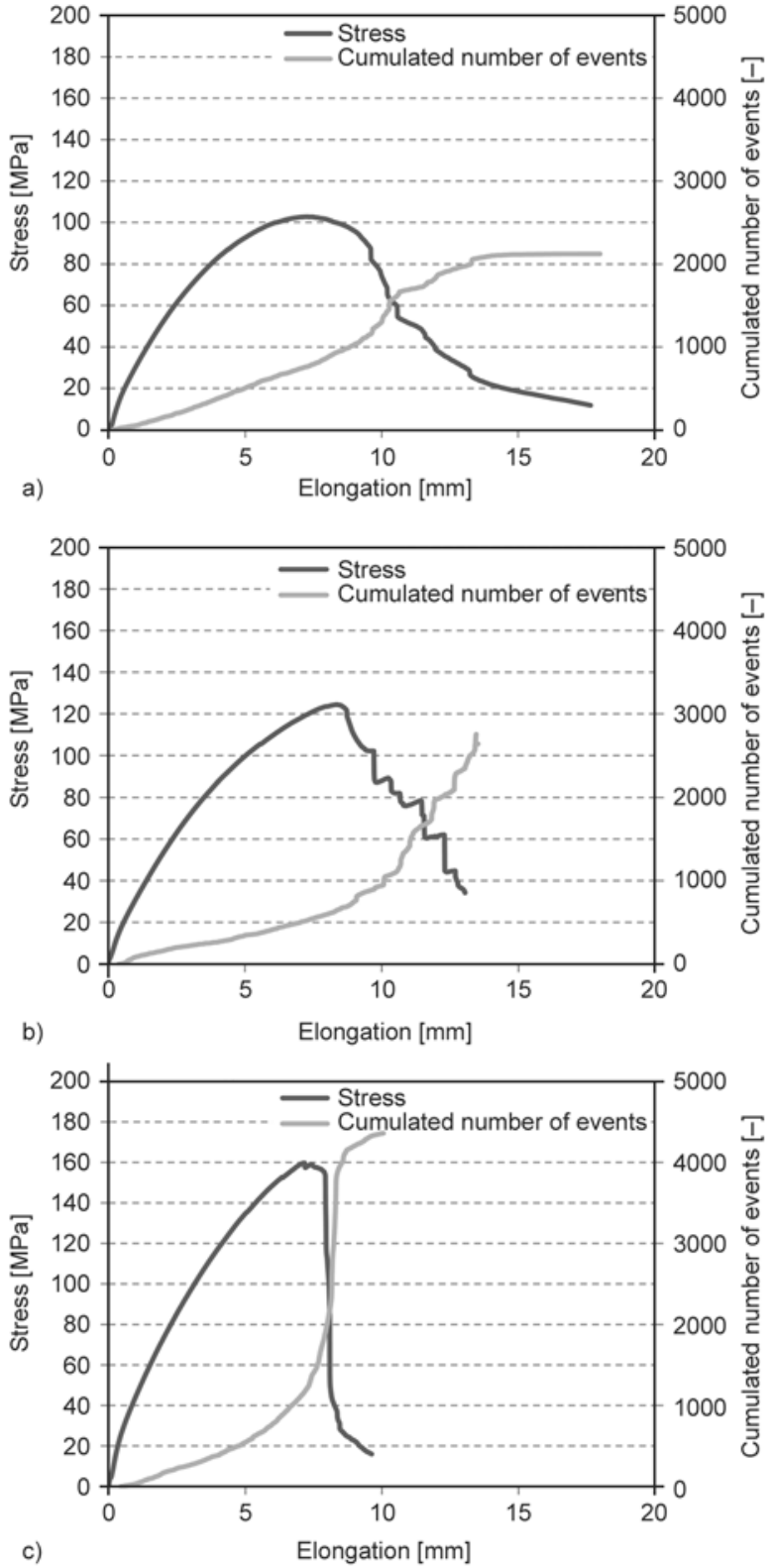

Figure 4. Tensile diagram and cumulated number of events of EOC (a), ePP (b) and rPP (c) CP SRPC

Figure 4 shows the course of the cumulated AE events as a function of tensile loading in CP-rein- 
forced SRPCs. The shape of the cumulative events as a function of elongation is conform with the finding in the literature [10], namely, as the temperature of pressing increases (EOC and ePP versus rPP matrix), the course of the corresponding curves changes from gradual to a steep stepwise rise. The latter indicates that the majority of the $\mathrm{AE}$ events occurred close to final failure.

The amplitude distributions in Figure 5 show that after the maximal force $\left(F_{\max }\right)$ is reached the proportion of high amplitude events drastically increases. Before $F_{\max }$ the fibers of the reinforcement structure only changed position and stretched, coupled with fiber-matrix debonding. This does not influence the tensile strength because the force continuously

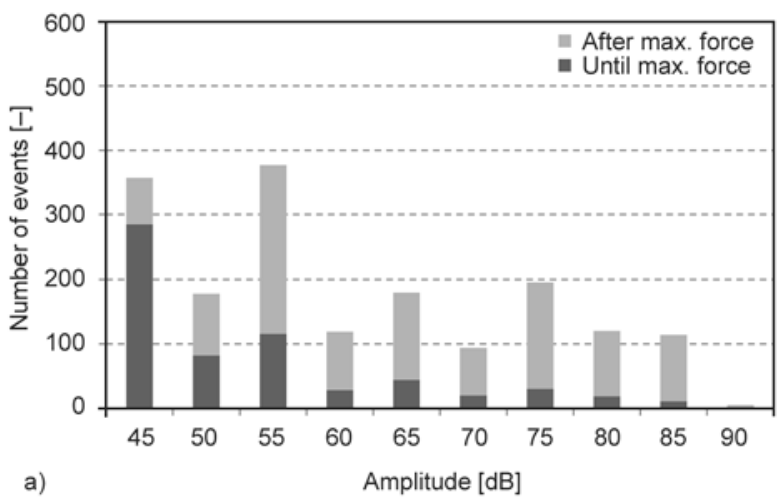

increases further on (cf. Figure 4). By contrast, above $F_{\max }$ the fibers started to break until the SRPC lost its load bearing capacity completely. In case of fabric reinforcement far more low-amplitude signals $(45 \mathrm{~dB})$ were detected for all the three matrices than for the other hPP reinforcing structures. These can be attributed to the tapes in the fabric which separate themselves from the matrix and start to slip within the composite [10]. This trend, but with different extent, was observed for all matrix materials and reinforcement structures.

Figure 6 shows the failure modes of SRPCs. As the processing temperature (EOC, ePP versus $\mathrm{rPP}$ ), and fiber-matrix adhesion increased (EOC versus ePP, rPP) the characteristic failure mode of specimens

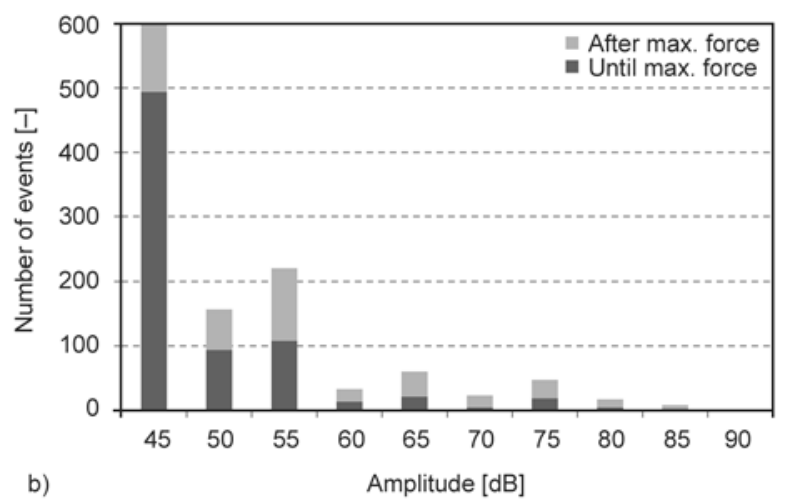

Figure 5. Amplitude distributions before and after maximal force in the case of an rPP matrix with CP (a), and fabric (b) reinforcement

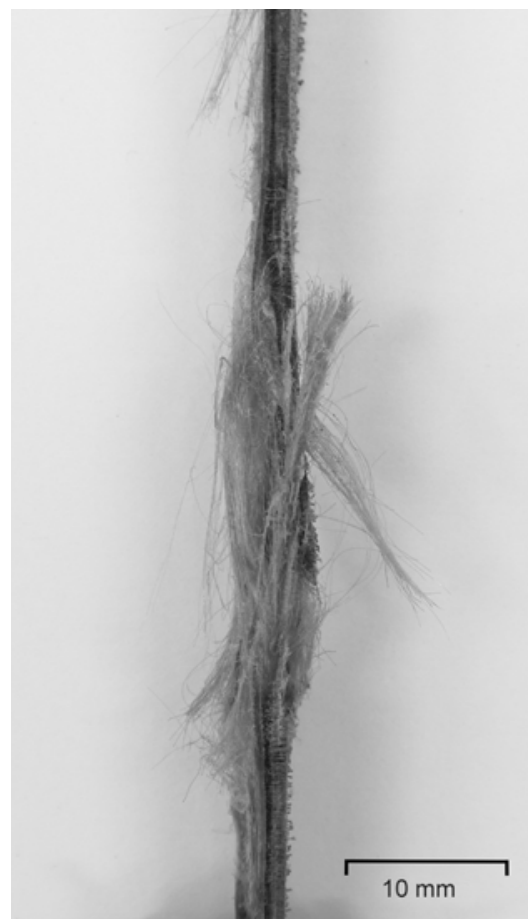

a)

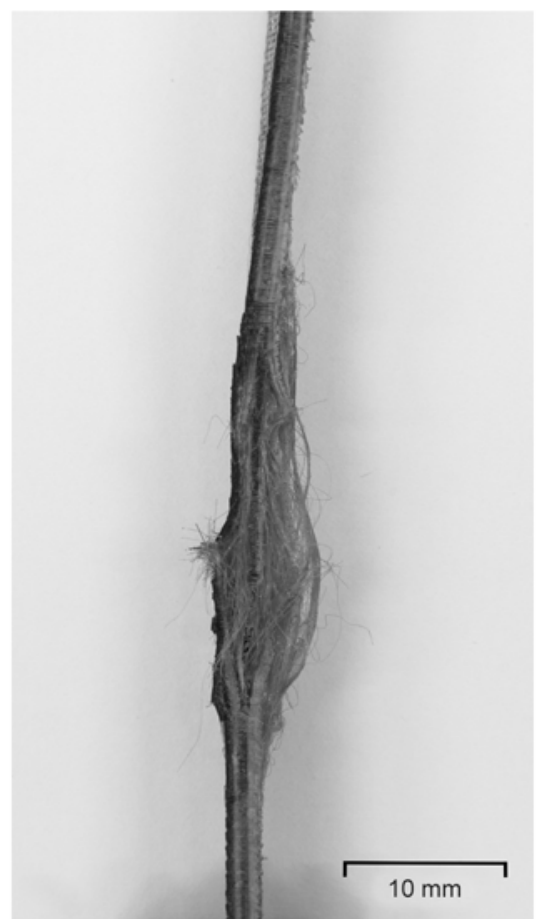

b)

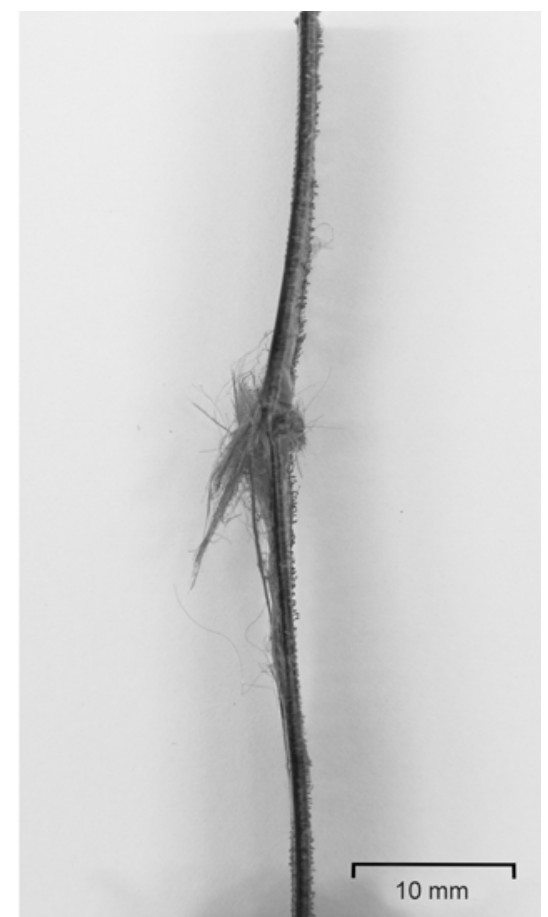

c)

Figure 6. Failure modes in the case of composites of EOC (a), ePP (b) and rPP (c) matrix and CP reinforcement 
shifted from fiber-matrix separation and layer delamination to fiber fracture. The fiber-matrix adhesion in the SRPC with EOC matrix was not as strong as in the other two cases because this is an ethyleneoctane copolymer and not PP as in the other SRPC combinations.

Figure 7 shows the number of events before reaching $F_{\max }$ and during the whole tensile test for various matrix materials and reinforcement structures. It can be seen that in the case of CP and UD reinforcements the detected number of events is higher when the Young's modulus of the matrix is higher. This can be attributed to the fact that a higher Young's modulus results in decreased acoustic damping, and thus signals generated further away from the microphone can also be detected [11]. In the case of fabric-reinforced composites the SRPC with rPP matrix behaves differently. The images of the polished cross-sections also suggest some differences of the fabric-reinforced composites in their acoustic activity. It can be seen that some tapes of the fabric may be melted in the rPP matrix-based composite, which was processed at higher temperature than those with the two other matrices. Moreover, in this
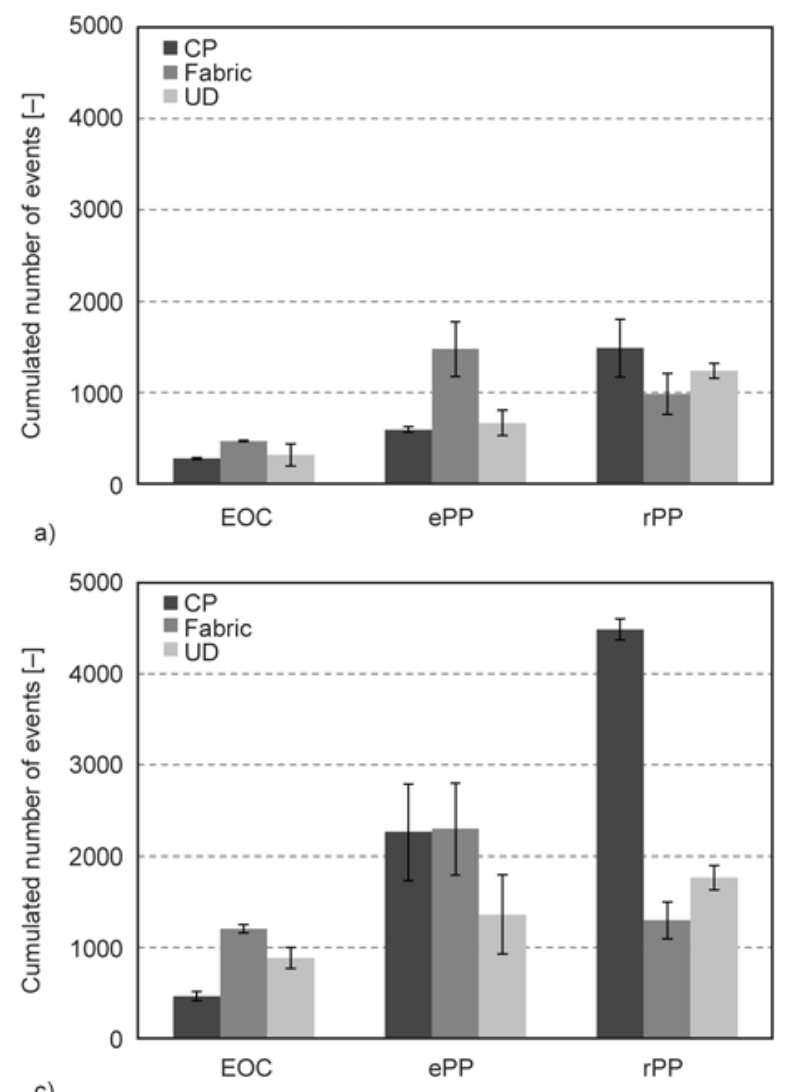

WF-reinforced rPP the tapes were not pre-tensioned (as opposed to SRPCs reinforced by the UD and CP systems), thus the relaxation of the tapes was more prominent during the manufacturing of the composite. The lower number of AE events for the EOCbased SRPCs can be attributed to the followings: i) this matrix is not PP-based, therefore its adhesion to the hPP fibers and tapes within the fabric is not as strong as in the case of the other two matrix materials, and ii) EOC, being practically a rubber, has the highest acoustic damping among the matrices used. It can also be observed that in the case of a CP structure there is considerable difference between the two loading directions, which can be explained by the asymmetry of the cross-section. The order of layers was not symmetrical to the median, in one case the layer on the side of the microphone was parallel to the direction of the load, while in the other case it was perpendicular to it. Since in fiber direction the damping of the individual layers is much lower than perpendicular to it, during the measurements in weft direction far more events were recorded because the external layer on the side of the microphone was parallel to the load.
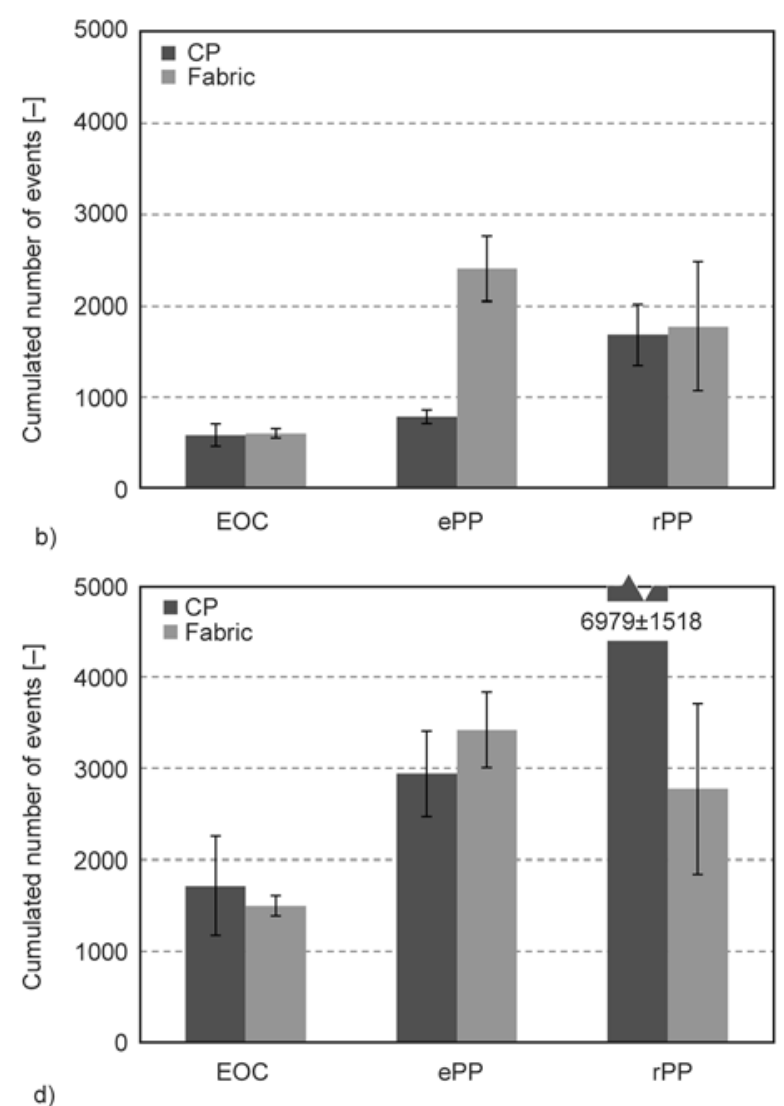

d)

Figure 7. Cumulated number of events in the case of different matrix materials in warp (a and c) and weft (b and d) direction until reaching the maximum force ( $a$ and $b$ ) and total ( $c$ and $d$ ) 


\section{Conclusions}

In this study polyolefin-based SRPCs were characterized in tensile tests during which the emitted acoustic signals were monitored. The mechanical properties of the composites significantly increased with all three kinds of reinforcement structures compared to those of the corresponding matrices. According to the results, $\mathrm{rPP}$ matrix and UD reinforcement produced the highest improvement in both tensile strength and Young's modulus. Tensile strength of this composite was more than six times higher than the matrix and the latter was nearly doubled. It was found that an increase in the Young's modulus of the matrix material is accompanied with an increase in the number of detected AE signals. This was attributed to the fact that a higher Young's modulus means lower acoustic damping, thus signals further away from the microphone can also be detected. It was shown that in the used test setup AE signals above $75 \mathrm{~dB}$ amplitudes can be unequivocally assigned to fiber fracture. Therefore it can be stated, that the realtime monitoring of the burst-type AE signals during loading is a useful tool to check the integrity of SRPC structures, to conclude failure initiation and failure sequence. $\mathrm{AE}$ signals in the highest amplitude range (specific amplitude values depend on the structure and experimental setup) can be assigned to the final fracture of the reinforcement aligned to the loading direction (usually fibers or tapes, also in woven architectures). It was also shown that an improvement in the fiber-matrix adhesion results in an increase in both the number and amplitude of acoustic events. Finally, the number of the emitted AE hits and their characteristics strongly depend on the matrix properties. A 'soft' rubbery matrix yields less signals and lower amplitude events than a 'hard' thermoplastic ones due to the difference in their acoustic damping.

\section{Acknowledgements}

This work was supported by OTKA Hungarian Scientific Research Fund by grants (K105257) in Hungary. This work is connected to the scientific program of the 'Development of quality-oriented and harmonized $\mathrm{R}+\mathrm{D}+\mathrm{I}$ strategy and functional model at BME' project. This project is supported by the New Széchenyi Plan (Project ID:TÁMOP-4.2.1/B09/1/KMR-2010-0002).

\section{References}

[1] Kmetty Á., Bárány T., Karger-Kocsis J.: Self-reinforced polymeric materials: A review. Progress in Polymer Science, 35, 1288-1310 (2010). DOI: $10.1016 /$ j.progpolymsci.2010.07.002

[2] Hine P. J., Unwin A. P., Ward I. M.: The use of an interleaved film for optimising the properties of hot compacted polyethylene single polymer composites. Polymer, 52, 2891-2898 (2011).

DOI: $10.1016 /$ j.polymer.2011.04.026

[3] Alcock B., Cabrera N. O., Barkoula N-M., Loos J., Peijs T.: Interfacial properties of highly oriented coextruded polypropylene tapes for the creation of recyclable all-polypropylene composites. Journal of Applied Polymer Science, 104, 118-129 (2007).

DOI: $10.1002 /$ app. 24588

[4] Chen J. C., Wu C. M., Pu F. C., Chiu C. H.: Fabrication and mechanical properties of self-reinforced poly (ethylene terephthalate) composites. Express Polymer Letters, 5, 228-237 (2011).

DOI: $10.3144 /$ expresspolymlett.2011.22

[5] Bárány T., Izer A., Czigány T.: High performance selfreinforced polypropylene composites. Materials Science Forum, 567-538, 121-128 (2007).

DOI: 10.4028/www.scientific.net/MSF.537-538.121

[6] Kmetty Á., Tábi T., Kovács J. G., Bárány T.: Development and characterisation of injection moulded, allpolypropylene composites. Express Polymer Letters, 7, 134-145 (2013).

DOI: $10.3144 /$ expresspolymlett.2013.13

[7] Zhuang X., Yan X.: Investigation of damage mechanisms in self-reinforced polyethylene composites by acoustic emission. Composites Science and Technology, 66, 444-449 (2006).

DOI: 10.1016/j.compscitech.2005.07.013

[8] Cabrera N. O., Alcock B., Klompen E. T. J., Peijs T.: Filament winding of co-extruded polypropylene tapes for fully recyclable all-polypropylene composite products. Applied Composite Materials, 15, 27-45 (2008). DOI: $10.1007 / \mathrm{s} 10443-008-9055-5$

[9] Romhány G., Bárány T., Czigány T., Karger-Kocsis J.: Fracture and failure behavior of fabric-reinforced allpoly(propylene) composite $\left(\mathrm{Curv}^{\circledR}\right)$. Polymers for Advanced Technologies, 18, 90-96 (2007). DOI: $10.1002 /$ pat.806

[10] Izer A., Stocchi A., Bárány T., Pettarin V., Bernal C., Czigány T.: Effect of the consolidation degree on the fracture and failure behavior of self-reinforced polypropylene composites as assessed by acoustic emission. Polymer Engineering and Science, 50, 2106-2113 (2010). DOI: $10.1002 /$ pen.21741

[11] Kim K. S., Lee K. I., Kim H. Y., Yoon S. W., Hong S. H.: Dependence of particle volume fraction on sound velocity and attenuation of EPDM composites. Ultrasonics, 46, 177-183 (2007). DOI: $10.1016 /$ j.ultras.2007.01.010 